\title{
Contra Kant y Schopenhauer. La afirmación nietzscheana
}

\author{
ÉRIC BLONDEL
}

La cuestión de la afirmación en Nietzsche es una cuestión clásica, por no decir banal. Pero es también una cuestión trampa. Pues a menudo se pregunta con cierta irritación cuáles son los valores, la moral, las verdades afirmadas por Nietzsche, ante la impresión que dan sus escritos de cuestionar todo, criticar, atacar, subvertir; en suma, se pregunta (y la cuestión es tan legítima que Nietzsche la ha tematizado como la respuesta al nihilismo que es su consecuencia inevitable) ¿qué queda tras el trabajo de zapa del que habla el prefacio de Aurora ${ }^{1}$ y la devastación de la que presume Nietzsche al calificarse como 'dinamita'? Pero la trampa en la que les gustaría hacer caer a Nietzsche (y a sus intérpretes) es que, en cuanto afirmador, no puede evitar aparecer como un idealista: un metafísico, un moralista, un asno, un camello, un filósofo enfermo de ontología. Por ejemplo, a Nietzsche le gusta presentarse como heraclitiano, como pensador de la inocencia del devenir, y cuestionar todas las formas de ontología metafísica, pero si él termina afirmando que la voluntad de poder es la esencia íntima del ser y que «este mundo es voluntad de poder -y nada más», podemos sin dificultad asimilarlo a Schopenhauer, dándole la mano en el cajón de la ontología. QED (firmado por Heidegger entre otros). Lo mismo para la moral, el conocimiento, la verdad, la ciencia, de tal manera que de afirmación en afirmación, y de llamada a los creadores en invocación profética a los filósofos nuevos, nos encontramos pronto con un Nietzsche provisto de una doctrina sistemática y que podemos mandar a vaticinar sobre la decadencia de nuestra época y a reclamar una moral de los señores y un orden nuevo...

Sin embargo, el amor fati es desde luego una afirmación de la realidad (o del Ser), porque consiste en que «nadie quiera nada de otra manera, ni hacia adelante, ni hacia atrás, ni por los siglos de los siglos». Y la Heiterkeit, el buen humor, antítesis afirmativa del resentimiento y de todas las negaciones de la

${ }^{1}$ Aurora, Prefacio $\$ 1$. 
vida por la moral, es ciertamente una afirmación gozosa de sí mismo y de la realidad, un antídoto al pecado, una manera de decir sí a lo que se es, de no desear ser distinto, una manera de devenir lo que se es, «de decir: ¡Oídme! Pues yo soy así y así. ¡Sobre todo, ningún quiproquo a mis expensas!», la forma moral de «decir sí» (Ja-Sagen) a sí mismo y al mundo.

Pero ¿en qué consiste entonces afirmar(se)? Con el «decir sí», la aprobación en palabras y en actos (Ja-Sagen, Ja-Tun), Nietzsche glorifica la potencia y la fuerza del Ser. Es un Gloria a sí mismo, su Jauchzet, frohlocket en la inmanencia. Denunciando sin cansancio (es su leitmotiv) el 'idealismo' (más que la metafísica), Nietzsche podría ser llamado un realista. Quisiera ilustrar aquí la paradoja (¡vergonzosa!) de una especie de ontología, de realismo ontológico en Nietzsche. Ahora bien, como realista en este sentido preciso, Nietzsche se hace parmenídeo y platónico: el ser es, el no-ser no es. Lo que se afirma es lo real ('la realidad', término-clave, ritornelo de Nietzsche). ¿Qué es lo real? Lo que se afirma, lo que se presenta, lo que se manifiesta, lo que se da aquí y ahora. La diferencia con Platón es precisamente que lo que se afirma no es precisamente el deber-ser, el ser en sí, sino el ser, que precisamente se confunde con lo sensible, con lo que se me ofrece hic et nunc, como devenir, como apariencia, como afecto: aquello de lo que soy afectado, lo que me afec$t a$. El realismo de Nietzsche es una 'ontología' de la realidad como devenir y afecto, que a la vez se duplica en una doctrina de la salud como parusía de la inmanencia, y 'buen humor' como aprobación de lo que me afecta (por oposición al resentimiento). Yo estoy bien como soy, el mundo está bien como es: como pasión, como afecto, como ser afectado, como Leidenschaft donde el mundo se me da, yo me afirmo como aprobación de lo que el mundo como totalidad hace de mí: amor fati. En el $\S 8$ de los «Cuatro grandes errores» del Crepúsculo de los ídolos, Nietzsche enuncia su 'teodicea', o más bien su 'cosmodicea', su justificación del mundo por sí mismo. «Yo soy así y así». «¿Qué es más indispensable que el buen humor?» Ecce homo, con sus cuatro gloriosas pretensiones afirmativas: Por qué soy tan sabio, por qué soy tan inteligente, por qué escribo tan buenos libros, por qué soy una fatalidad, es una manera de realizar esta afirmación, de transformar unas 'confesiones' en 'recuerdos de egotismo', de mudar un tratado de moral en autoglorificación y en acción de gracias, de manifestar y afirmar fieramente el buen humor bajo forma de chifla e insolencia, sirviendo su pretenciosa jactancia, su vanagloria, de antítesis al resentimiento y a la mala conciencia características de la moral.

Utilizando básicamente tres textos ${ }^{2}$, quisiera hacer ver cómo Nietzsche intenta llevar al lector y a su filosofía a la afirmación, y explicar en qué consiste afirmar, por medio, entre otras cosas, de una debate crítico con Kant (deber) y Schopenhauer (negación del querer-vivir). Se podría esquematizar este pro-

${ }^{2}$ El Anticristo 15 y 11, Ecce homo, «El nacimiento de la tragedia» §2. 
pósito diciendo que Nietzsche asocia la afirmación del ser (Heiterkeit) a la negación del deber-ser. En efecto, en el marco de la problemática de la decadencia, Nietzsche analiza el sufrimiento como la parte de no-ser que comporta el ser, como una realidad siniestrada o robada (verunglückte Realität), porque la pasividad engendra el resentimiento que caracteriza a la moral. La serie sufrimiento-pasividad-debilidad-decadencia sería una especia de entropía vital, a los ojos de un Nietzsche en cierto modo bergsoniano, deleuziano o más bien espinozista (antítesis de la 'acción' y de la 'pasión'). Por otra parte, bajo la perspectiva de una especie de contra-teodicea o de cosmodicea, Nietzsche alía juntos:

a) por una lado, el Ja-Sagen en palabra y en acto (Bejahung, conformidad), la rehabilitación del ser, de la realidad, frente al ideal, a la moral, al 'mundo verdadero', la reafirmación de la prioridad de lo sensible, de la vida y de las pasiones sobre lo inteligible, la razón, la representación y el deber-ser;

b) por otro lado, una negación del deber-ser como nihil, como 'nocivo', como enfermedad, como escapatoria. La realidad es la única y última instancia: el amar como necesario, es el amor fati, la verdadera teodicea de Nietzsche, puesto que amar es aprobar, considerar una realidad singular como un bien y tal cual es, «no quererla de otra manera».

La teodicea de Nietzsche se expresa ante todo mediante fórmulas cómicas de tono burlesco, yuxtaponiendo nociones morales o soteriológicas y realidades fisiológicas prosaicas. «De hecho, hasta mi 'última madurez, no he hecho más que comer mal -por decirlo en términos morales, de una manera 'impersonal', 'desinteresada', 'altruista', por el mayor bien de los cocineros y de otros hermanos en Cristo. Por ejemplo, mediante la cocina de Leipzig, en la época de mi primero estudio de Schopenhauer, me ejercitaba muy seriamente en negar mi 'querer-vivir'» ${ }^{3}$. «El pensar se aprende como se aprende la danza, y precisamente porque es una especie de danza... ¿Quién entre los alemanes conoce todavía ese ligero estremecimiento que el pie ligero, en el ámbito del espíritu, hace pasar por todos los músculos! La actitud rígida y zoquete del espíritu, la mano entumecida para coger las cosas- es hasta tal punto alemán, que el extranjero no lo distingue de la cultura alemana. El alemán carece de tacto para captar los matices... El sólo hecho de que los alemanes hayan podido soportar a sus filósofos, comenzando por el más desmedrado de los tullidos del concepto, el gran Kant, dice ya mucho sobre la gracia de los alemanes $»^{4}$. Y por lo que concierne a Schopenhauer, El nacimiento de la tragedia «huele a hegelianismo hasta la indecencia, sólo algunas fórmulas conservan el tufo de enterrador que se acompaña a Schopenhauer» ${ }^{5}$.

\footnotetext{
${ }^{3}$ Ecce homo, «Por qué soy tan inteligente», § 1 .

${ }^{4}$ Crepúsculo de los ídolos, «Lo que los alemanes están perdiendo», § 7.

${ }^{5}$ Ecce homo, «El nacimiento de la tragedia», § 1.
} 
Los lectores que abordan Nietzsche y sucumben a sus seducciones ignoran que se lo debe casi todo a este filósofo, su único maestro en la materia ${ }^{6}$. Para elaborar su filosofía de la afirmación, Nietzsche, en efecto, podríamos decir que, ha recogido el conjunto de los temas de Schopenhauer, conservándolos bajo otras denominaciones o contentándose casi sólo con invertir su sentido, y sirviéndose de ellos como de unos negativos que él convierte en positivos. Cuando Nietzsche habla de filósofos o de metafísicos (lo que hace con menos frecuencia de lo que ha pretendido Heidegger) es siempre o casi siempre Schopenhauer a quien tiene presente, personalmente o como epítome o manual superior de historia de la filosofía (supliendo así la ignorancia de Nietzsche en lo que respecta a Spinoza, Platón e incluso Kant).

El primer tema retomado es la distinción entre voluntad y representación. Nietzsche la conservará todo a lo largo de su obra, bajo la forma de su teoría de los instintos, de su insistencia en el carácter principalmente inconsciente de los afectos y de la denuncia de la sobrestimación de la razón, de lo consciente y de los ideales. El 'realismo' de Nietzsche, en su oposición bien conocida al idealismo, debe mucho a la concepción schopenhaueriana de la voluntad como impulso inconsciente y sin finalidad, como instinto y como cosa en sí, es decir, realidad última de las cosas, irracional y caótica, que domina a la conciencia, órgano superficial sobrestimado ${ }^{7}$.

El segundo tema es el de lo que Michel Henry, para caracterizar la idea schopenhaueriana y nietzscheana de la voluntad, llama 'ser afectado'. La voluntad es pre-representativa, inconsciente y desprovista de lógos, de télos y de término (ikanon). La 'voluntad' designa lo que yo 'sufro': los términos que utiliza Nietzsche, cuando no habla de 'afectos' o de 'instintos', son los de Leidenschaft o de Passion, lo que puede prestarse a confusión. Nietzsche no entiende por ellos sólo las pasiones como la cólera, el rencor o el amor, sino más bien todo lo que me sobreviene como experimentado (leiden, patior), no sólo en el sentido de un afecto sufrido, sino sobre todo en el sentido de lo que es experimentado y sentido antes incluso de ser representado (el afecto, el patior, el Leiden, lo que Nietzsche llama a veces el Pathos en el sentido griego y alemán, que indica el sentido instintivo, el instinto que juzga antes de pensar discursivamente y conscientemente -por ejemplo, el Pathos der Distanz, sentido de la distancia). Como en Spinoza, este ser afectado está en proporción a la pasividad (passio) del modo del sujeto que sufre ideas inadecuadas: la debilidad designa el hecho de dejarse sobrepasar y desbordar por sus afectos y afecciones hasta el punto de tener que negarlos o negar la realidad para supe-

\footnotetext{
${ }^{6}$ Sobre Nietzsche y Schopenhauer, cf. entre otros F. Decher, Wille zum Leben - Wille zur Macht, Königshausen, Würtzburg, 1984; y M. Haar, «La critique nietzschéenne de Schopenhauer», en Par-delà le nihlisme, PUF, Paris, 1998.

${ }^{7}$ Cf. KSA XIII 11[83], 11[145], 14[144] y 14[145].
} 
rarlos. El Pathos, el ser afectado, es en el débil, sufrimiento, enfermedad, pasividad. Es por el riesgo de esta pasividad sufriente por lo que Nietzsche toma precauciones definiendo la voluntad de poder como voluntad de más poder, como acrecentamiento, «No la satisfacción, sino más poder» ${ }^{8}$.

En tercer lugar, Nietzsche retoma de Schopenhauer la idea, abocada a un ilustre destino filosófico y psicoanalítico, que la representación es menos el Erscheinung, el fenómeno de la voluntad, que su Schein, su ilusión. Para él, la conciencia es el órgano más superficial del cuerpo, la razón es un instrumento impotente al servicio de las pulsiones, y el ideal es un enmascaramiento mendaz de los instintos que actúan en lo más profundo del cuerpo. Nietzsche llega incluso a reducir la conciencia y la razón a una especie de síntoma del cuerpo, a una interpretación (más o menos pertinente y fecunda) de lo que siente, hace y dice el cuerpo: la «pequeña razón». Hasta el punto de que si el cuerpo es una entidad única que Nietzsche concibe en una visión monista, el espíritu no es exterior a él, sino que no es más que uno de sus aspectos o manifestaciones, una instancia interna: el cuerpo es razón y la razón es corporal, cuya unidad no está producida por la conciencia o razón, bajo la garantía de una síntesis subjetiva consciente, sino por un principio de unidad indisolublemente físico y psíquico, el sí mismo (Selbst). «El cuerpo es una gran razón, una pluralidad unánime [mit einem'Sinne], una guerra y una paz, un rebaño y un pastor. [...] Es un instrumento de tu cuerpo esa pequeña razón tuya, hermano mío, esa que tú llamas 'espíritu', un pequeño instrumento y un pequeño juguete de tu gran razón. Yo, dices, y estás orgulloso de esta palabra. Pero lo que hay de más grande en lo que tú renuncias a creer es tu cuerpo y su gran razón. Inteligencia y espíritu [Sinn und Geist] son instrumentos y juguetes: tras ellos se halla además el sí mismo [Selbst] [...] El sí mismo busca con los ojos del espíritu, escucha con las orejas del espíritu» ${ }^{9}$.

Cuarto tema schopenhaueriano 'retomado' pero desviado por Nietzsche: la negación del querer-vivir. No se trata de insinuar que Nietzsche se queda con esta idea. Pero hay que hacer notar que si habla sin cesar de afirmación es por oposición a la solución schopenhaueriana, la cual, según él, define propiamente a la debilidad -tema y noción propiamente nietzscheanos. No entenderemos la significación de la insistencia de Nietzsche sobre la afirmación y la creación sin referirnos al análisis que hizo Schopenhauer de la negación del querer-vivir, bajo sus dos formas por así decirlo canónicas: el arte y la moral. El rechazo y la crítica de un arte concebido como salud fuera de este mundo (Platón retomado por Wagner a la moda 'cristiana') y la contestación permanente de una moral de la piedad, del altruismo y del desinterés (que deberíamos traducir más propiamente por 'abnegación', en el sentido de 'negación

${ }^{8}$ El Anticristo§2.

${ }^{9}$ Así habló Zaratustra I, «De los despreciadores del cuerpo». 
del yo', 'des-egoización': Selbstlosigkeit, Entselbstung) no podría entenderse sin el trasfondo de la doctrina schopenhaueriana. Ahora bien, hay que señalar que la negación del yo, del ego(ísmo) en una moral de la piedad (Mitleid), y de la abnegación (Selbstlosigkeit), halla por así decirlo su acabamiento en una moral del rebaño: el rebaño me permite no ser yo, me permite obedecer renunciando a mi voluntad propia, destruir mi yo para someterlo a una instancia exterior, lo que se llama someterse al deber, entendiendo por ello dejar que nuestra voluntad sea devorada por una constricción venida de lo alto y de fuera. Tal es por lo menos la interpretación que Nietzsche se deja imponer por una tradición alemana inspirada por las sentencias antikantianas de Schiller y Heine: el deber se caracteriza por la renuncia a satisfacer las inclinaciones, y no sólo hay que distinguir el deber de la inclinación, sino además fundar el cumplimiento del deber sobre la repugnancia, es decir, sobre el disgusto y la negación de sí mismo ${ }^{10}$.

Se entiende entonces qué idea le gusta a Nietzsche dar de la moral de Kant. El imperativo categórico ya no es formulado como la universalización de la máxima, sino como una objetividad trascendente cuyo principio subjetivo habría sido eliminado radicalmente, hasta el punto de que el deber sería una 'abstracción', es decir, una negación de toda voluntad subjetiva o inclinación, abstracción caracterizada por la 'impersonalidad' y asimilada a la universalidad ${ }^{11}$. En estas condiciones, es lógico que Nietzsche pueda asimilar el imperativo categórico a cierta represión y a unas exigencias monstruosas («deber 'impersonal', sacrificio al Moloch de la abstracción» ${ }^{12}$ ) y le encuentre «cierto resabio de sangre y de tortura ([...] incluso en el viejo Kant: el imperativo categórico huele a crueldad...)» ${ }^{13}$. Podemos así remontar a esta misma interpretación (tendenciosa bajo un punto de vista estrictamente kantiano) la insistencia paralela de Nietzsche sobre la conexión entre el imperativo categórico y el postulado de la razón práctica concerniente a la existencia de Dios: el deber toma el lugar metafísico de Dios en un sistema que, teóricamente, ha recusado la existencia de Dios, precisamente porque él representa el residuo irreductible de una trascendencia absoluta ${ }^{14}$. Es significativo que Nietzsche no concibe el deber sino como objeto de respeto (y no como lo que no obtiene su objetividad sino de la universalización de una

${ }^{10} \mathrm{Cf}$. V. Delbos, La philosophie pratique de Kant, cap. I.

${ }^{11}$ El Anticristo $\$ 11$. La equivalencia entre la universalidad y la impersonalidad, como negación de todo particularismo concreto, es una idea romántica destinada a demoler la Ilustración.

${ }^{12}$ Ibid.

${ }^{13}$ La genealogía de la moral II, §6.

${ }^{14}$ El Anticristo $\$ 10$ : «La idea de la moral como esencia de Dios».

${ }^{15}$ Ibid. 
máxima subjetiva) ${ }^{15}$. Es interesante hacer notar en este punto que Nietzsche cree poder hablar de la 'virtud' en Kant, y que quiera ver en el deber «una virtud que no deriva más que del sentimiento de respeto hacia la idea de 'virtud'», como si la idea de virtud se fundase sobre una trascendencia autofundada, como si -y es efectivamente lo que Nietzsche cree poder escribir- fuera asimilable al «Bien en sí» ${ }^{16}$.

En torno a la relación entre Nietzsche y Schopenhauer podemos proponer en principio la idea general siguiente: Nietzsche, inscribiéndose completamente en el cuadro de la problemática filosófica de Schopenhauer y retomando sus tesis principales sobre la concepción de la realidad (voluntad trágica, esencia pulsional e inconsciente de la voluntad, carácter ilusorio de la representación, la moral y el arte como negaciones de la voluntad, lo que define la debilidad), invierte completamente el sentido y el alcance de la doctrina, la retoma dándole una valor negativo, afectando sus nociones principales de un signo negativo. Nietzsche invierte esta doctrina en un pensamiento de la afirmación del querer-vivir, concibe la representación como el síntoma de voluntades escondidas (genealogía o 'psicología'), con la divergencia considerable (y paradójicamente de inspiración kantiana) de que la voluntad ya no es una substancia, un ser metafísico, sino una pluralidad que se escapa a toda captación, un puro aparecerse sin en sí, una 'apariencia' sin fondo ni esencia, un principio de superación incesante de sí.

Lo que propone entonces Nietzsche, con respecto al problema central del sufrimiento $^{17}$, es una contra-doctrina de la salud, una anti-soteriología. Esta doctrina, que acostumbra ser caracterizada en este sentido como trágica, halla su principio en la asunción del ser como sufrimiento (Leidenschaft, Selbstüberwindung, conflicto, 'guerra'), en lugar de lo que ocurre en todas las doctrinas decadentes y nihilistas, desde Epicuro a Schopenhauer pasando por el cristianismo, de intentar escapar de él por todos los medios, tales como la paz del alma, el bienestar, la ataraxía, la negación del querer-vivir, o también el deber, como supresión de todas las contradicciones y violencias. Bajo este punto de vista hay que entender los llamamientos de Nietzsche a la guerra ${ }^{18}$, así como la noción central de 'gran salud' ${ }^{19}$. «Toda filosofía que pone la paz más arriba que la guerra, toda ética que presenta una versión negativa del concepto de felicidad, toda metafísica y toda física que reconocen un final, un estado último del tipo que sea, toda aspiración principalmente estética o religiosa a un 'al margen de', un 'más allá', un 'fuera de' o un 'por encima de',

${ }^{16}$ El Anticristo $\$ 11$.

${ }^{17}$ Véase los análisis penetrantes de P. Wotling, Nietzsche et le problème de la civilisation, PUF, Paris, 1995, pp. 137-154.

${ }^{18}$ Cf. Crepúsculo de los ídolos, prefacio, y La gaya ciencia, prefacio §2.

${ }^{19}$ La gaya ciencia $\$ 382$. 
autoriza a preguntarnos si no es la enfermedad lo que ha inspirado a la filosofía $»^{20}$. «El sufrimiento es sin duda una parte esencial de toda existencia», escribe Nietzsche en un fragmento póstumo ${ }^{21}$. Ante el hecho del sufrimiento y la forma religiosa, moral, 'cristiano-platónica' de abordar este sufrimiento, Nietzsche rechaza toda escapatoria, todo esquivar la realidad. Él pone, al contrario, todos sus esfuerzos filosóficos en hacer reentrar esta realidad en la vida humana, y por tanto en la filosofía, en la sabiduría, en el texto, en el pensamiento, siendo la fuerza el nombre para la afirmación-afrontamiento de la realidad consigo misma, en la lucha (guerra) vital, en el sufrimiento de vivir. «Lo que caracteriza la actitud trágica ante la realidad, es la capacidad de superar el sufrimiento, y no la actitud de guardarse de él» ${ }^{22}$. Vivir, ser real, sería asumir, afirmar el sufrimiento como realidad ${ }^{23}$. En contra de la blasfemia de Schopenhauer: «Nosotros somos en el fondo algo que no debería ser; por eso, dejemos de existir» ${ }^{24}$, contra la idea (negación de la inocencia del devenir, hinchada de resentimiento) del mismo Schopenhauer: «Todo gran sufrimiento, sea físico o moral, expresa lo que merecemos: puesto que no podría afectarnos si no lo mereciésemos» ${ }^{25}$, Nietzsche habla de amor fati $^{26}$, de «fatalidad de la naturaleza que no debe ser separada de la fatalidad de todo lo que ha sido y de todo lo que será» ${ }^{27}$. Y contra Kant declara que «es absurdo querer torcer la propia naturaleza hacia fin alguno» ${ }^{28}$.

$\mathrm{El}$ amor (amor fati ${ }^{29}$, «pues yo te amo, o eternidad $»^{30}$ ) es reconocimiento del ser como singularidad y presencia concreta. El deber-ser, que presupone por principio que el ser no debería ser, es una negación del ser, dicho muy propiamente un odio, que se expresa como rencor, resentimiento, calumnia, mentira consagrada. ¿En nombre de qué ser ideal, de qué bien en sí, el ser real no debería ser? La teodicea de Nietzsche es una apología de lo sensible, una glorificación de la presencia, de la parusía del ser como sensible, como pasión, como Leidenschaft, como ser afectado y afecto procedente de la realidad. El eterno retorno es la idea de un retorno eterno de lo idéntico (Wiederkehr

${ }^{20}$ La gaya ciencia, prefacio $\$ 2$.

${ }^{21}$ KSA XI 626, 39[16]. Cf. Más allá del bien y del mal §259.

${ }^{22}$ P. Wotling, op. cit., p. 144.

${ }^{23}$ Crepúsculo de los ídolos, prefacio.

${ }^{24} \mathrm{~A}$. Schopenhauer, El mundo como voluntad y representación, vol. II, cap. XLI: «Sobre la muerte y su relación con la indestructibilidad de nuestro ser en sí».

${ }^{25}$ Citado por Nietzsche en Crepúsculo de los ídolos, «Los cuatro grandes errores» §6 (A. Schopenhauer, op. cit., vol. II, cap. XLVI).

${ }^{26}$ Ecce homo, «Por qué soy tan inteligente» $\$ 10$.

${ }^{27}$ Crepúsculo de los ídolos, «Los cuatro grandes errores» $\$ 8$.

${ }^{28}$ Ibid.

${ }^{29}$ Ecce homo, «Por qué soy tan inteligente» 10.

${ }^{30}$ Ditirambos de Dioniso, «Gloria y eternidad». 
des Gleichen), la perenización, la eternización de lo que es, de lo que se da aquí, mientras que el sufrimiento inspirado por el resentimiento indica una falta de ser en un ser que, por impotencia, por falta de ser, querría que las cosas fueran de otra manera. La única liturgia, la única 'moral', debe ser la bendición («no rezar, sino bendecir»), el ditirambo, el amor, el decir-sí, la aprobación, la gracia dada a la singularidad eterna de la realidad, a la positividad absoluta del ser tal cual es. Lo que debe ser afirmado es el ser porque es, en cuanto que es, sin reservas, ni futuro, ni cambio. No Deus sive natura, sino Deus aut natura: Dios o bien, excluyendo a la naturaleza. Como escribe Nietzsche, «non alia, sed haec vita sempiterna ${ }^{31} »$, no es otra vida sino -ésta la que es eterna. Nada de Kyrie eleison, nada de Dios misericordioso, nada de Mitleid: inocencia del devenir, Unschuld des Werdens. Inocencia del devenir, pero también ausencia de falta o de deuda del devenir: el devenir, el ser como devenir no nos debe nada.

Así hay que entender las últimas líneas de ese texto realmente clásico y fundamental que es el parágrafo 15 de El Anticristo: «Este universo de pura ficción (la moral y la religión en el cristianismo) se distingue completamente, en desventaja suya, del de los sueños, en que éste refleja la realidad, mientras que aquél falsea, devalúa y niega la realidad. Una vez inventada la idea de naturaleza para oponerla a la de 'Dios', hacía falta que el término 'natural' fuese sinónimo de 'condenable', -este universo de pura ficción toma sus raíces del odio hacia el natural (-¡la realidad!--) ${ }^{32}$, es la expresión de un profundo malestar ante lo real... Pero he aquí que lo explica todo. ¿Quién es el único que tiene motivos para escapar de la realidad mediante la mentira? Quien sufre de ella. Pero sufrir de la realidad supone ser una realidad estropeada... La preponderancia de los sentimientos de desplacer sobre los de placer es la causa de esta moral y de esta religión ficticias: ahora bien, tal preponderancia suministra la fórmula de la decadencia» ${ }^{33}$. La afirmación, la fuerza, es la potencia del ser. Sufrir es estar débil, es decir, es un ser disminuido, un ser 'impotente'. Casi parece estar leyendo la Ética de Spinoza.

Ahora podemos abordar, para comentarlo en detalle, el texto del parágrafo 11 de El Anticristo, donde Nietzsche, frente a la moral de Kant y a su idea del deber, y al precio de algunos errores en cuanto a la letra del kantismo, define una vez más lo que entiende por afirmación. Este parágrafo se sitúa en un pasaje donde Nietzsche declara «hacer la guerra» al instinto de teólogo $\mathrm{o}^{34} \mathrm{y}$ prosigue su polémica sosteniendo que la 'filosofía', sobre todo la de Kant,

${ }^{31}$ KSA IX 652, 15[54].

${ }^{32}$ Este paréntesis con el punto de exclamación podría servir de epígrafe o de lema a toda la filosofía de Nietzsche.

${ }^{33}$ El Anticristo $\$ 15$.

${ }^{34}$ El Anticristo $\$ 9$. 
está «corrompida por la sangre de teólogo»: «el éxito de Kant no es más que un éxito de teólogo» ${ }^{35}$. Esta paradoja, insostenible respecto a la filosofía teórica, se apoya en una argumentación en principio brusca, inaugurada por Heine, según la cual, «gracias a Kant, un atajo fue abierto hacia el ideal antiguo, el ideal del 'mundo verdadero', la idea moral como esencia del mundo» ${ }^{36}$. Que Nietzsche continua: «Una palabra más sobre Kant moralista. Una virtud debe ser nuestra invención, nuestra legítima defensa y nuestra necesidad más personales: en cualquier otro sentido no es más que un peligro. Lo que nuestra vida no necesita, la perjudica: una virtud que no deriva más que del sentimiento de respeto hacia la idea de 'virtud', en el sentido en que lo entendía Kant, es perjudicial. La 'virtud', el 'deber', el 'Bien en sî', el Bien caracterizado por la impersonalidad y la universalidad pamplinas en las que se expresan el declive, la última debilitación de la vida, la chinería königsberguense. Es lo contrario de lo que exigen las más profundas leyes de la conservación y del crecimiento: que cada uno se invente $s u$ virtud, $s u$ imperativo categórico. Un pueblo perece cuando confunde su deber con la idea del deber en general. Nada destruye más profundamente, más íntimamente que todo deber 'impersonal', que todo sacrificio al Moloch de la abstracción ${ }^{37}$. Nótese ante todo que Nietzsche no duda en proferir exageraciones, en enunciar afirmaciones completamente erróneas que son al mismo tiempo contrasentidos, que demuestran que el autor de El Anticristo ignoraba la letra strictu sensu de la doctrina kantiana. Los términos de 'virtud' y de 'Bien en sí' no son propiamente kantianos, sino que pertenecen a la filosofía antigua, desde Platón a los estoicos: Kant sólo habla de virtud de manera negativa ${ }^{38}$ o en referencia al epicureismo y al estoicismo ${ }^{39}$. En Kant, la 'virtud' no 'deriva' (aus) de un sentimiento de respeto hacia la idea de 'virtud': dicho respeto es sólo el 'móvil subjetivo', mientras que el fundamento de la moralidad es sólo la ley. «Así el respeto hacia la ley no es un móvil para la moralidad, sino que es la moralidad misma, considerada subjetivamente como móvil, mientras que la razón pura práctica [...] da autoridad a la ley que sólo ahora tiene influencia ${ }^{40}$. Si es verdad, como escribe Kant en los Fundamentos, que «el deber es la necesidad de realizar una acción por respeto a la ley», el respeto no es el fundamento de la moral, sino que manifiesta sólo la influencia de la ley moral como móvil. En tercer lugar, 'el Bien' (término que no forma parte de la terminología kantiana), o más bien el deber y la moralidad por respeto a la ley, no se «caracteriza por

\footnotetext{
${ }^{35}$ El Anticristo $§ 10$.

${ }^{36}$ Ibid.

${ }^{37}$ El Anticristo $\$ 11$.

${ }^{38}$ I. Kant, Fundamentos de la metafísica de las costumbres, sección II, comienzo.

${ }^{39}$ I. Kant, Crítica de la razón práctica, «Dialéctica de la razón práctica», libro II, cap. II.

${ }^{40}$ I. Kant, Crítica de la razón práctica, I, I, cap. III.
} 
la impersonalidad», sino por la universalidad. Ahora bien, estos conceptos no son en absoluto asimilables, el segundo no implica al primero, y la universalización de la máxima no implica el aniquilamiento de lo subjetivo, sino todo lo contrario, la integración y la garantía de los derechos (y deberes) de la persona en lo universal.

Sin embargo, a pesar o más allá de estos errores de interpretación, Nietzsche se sirve de esta imagen del kantismo para definir la afirmación. Lo hace precisando lo que él mismo entiende por virtud -lo que dejó de hacer a lo largo de todos sus escritos póstumos y que ha retomado en el parágrafo 2 de El Anticristo, al hablar de «virtud exenta de moralina» (moralinfreie Tugend). Subrayemos ante todo que Nietzsche utiliza un tono deontológico, hablando de una necesidad intrínseca: «una virtud tiene que $[m u s s]$...». A continuación el adjetivo posesivo es repetido y siempre subrayado: «Nuestra invención...» Nietzsche se refiere a una especie de sujeto, a un ego, o al menos a un centro de referencia subjetivo: esto presupone que en materia de acción, de práctica, de 'virtud', y por tanto de puesta en obra de pulsiones o de instintos, es decir, en el vivir, un 'sujeto' se constituye, como aquello mediante lo cual se expresa y actúa la voluntad de poder. Ésta no puede 'querer' más que constituyendo un ego, constituyéndose en algo subjetivo: la voluntad de poder implica la problemática de la constitución (o de la no-constitución) del ego ${ }^{41}$, siendo una voluntad fuerte la que se da un yo fuerte, una realidad egoísta (Selbstsucht $)^{42}$. Esta idea es confirmada y reforzada por los tres términos 'invención', 'legítima defensa' y 'necesidad'. La virtud, como fuerza de expresión de la voluntad de poder en una acción auténtica, es invención (Erfindung), ante todo en el sentido de que ella es comienzo, que ella toma su origen y su fuente, su energía misma, de un sujeto, que es su principio, en este sentido de que es primero: es lo que explicita el término, utilizado en otras partes por Nietzsche, de mandamiento. El mandamiento es comienzo (Nietzsche se acuerda quizá del término griego arché, que posee estos dos sentidos), mientras que la voluntad débil, que obedece, no hace más que seguir, es la de los seguidores, de los epígonos, de los que continúan (tradición, orden establecido, devoción a los ideales, sumisión a unas autoridades, falta de iniciativa y servilismo ante toda forma de trascendencia real o supuesta), en una palabra: del rebaño. «Legítima defensa» (Notwehr) quiere indicar aquí que, estando la vida constituida por una relación de fuerzas conflictivas, todas ellas en busca egoísta de dominación, vivir es imponer sus prerrogativas contra la pretensión de las otras fuerzas en juego, actuar es atacar para acceder a la potencia y salvaguardarla en vista de su acrecentamiento. Es evidente que este término hace aquí refe-

${ }^{41}$ Es lo que ha visto acertadamente Heidegger (en este punto).

${ }^{42} \mathrm{Cf}$. Ecce homo, «Por qué escribo tan buenos libros» §5: «Hay que tener un yo sólidamente cimentado...». 
rencia al struggle for life darwiniano, a la idea de que «lo que no me mata me hace más fuerte», que la vida es una «escuela de guerra $»^{43}$ donde la potencia es el envite del ataque y la defensa, según la descripción de la vida que Nietzsche desarrolla todo a lo largo del aforismo 259 de Más allá del bien y del mal (despojar, herir, violentar, explotar, oprimir, asimilar). Es lo sugerido por el término siguiente de 'urgencia' y por el término clave de 'peligro' al final de la frase, que subrayan que la acción, en conexión con la naturaleza de la vida, es un proceder por necesidad, penuria, adaptación, mediante la acción vital a unas circunstancias de vida o de muerte, de conservación de la vida, de presión de la voluntad de poder, que aumenta o perece.

En la segunda frase del texto, Nietzsche enuncia el principio por así decir metafísico de su pensamiento, su axioma ontológico. Este principio retoma la tesis fundamental de Schopenhauer: el ser es voluntad, cuya representación no es más que el aparecerse. La formulación de Nietzsche podría entonces ser explicitada así: lo que no condiciona nuestra vida es lo ideal, lo consciente, la racionalidad, por oposición a los instintos, a la fuerza, a la voluntad de poder. Pero todo aquello, siendo mero fenómeno, superficie, apariencia, ilusión, es el epifenómeno de la vida, y no la condiciona. Lejos de ser su condición, su principio y fuente, lo consciente, lo abstracto, lo racional, en resumen lo ideal, son defectos de ser, son el freno, el artificio que, mientras no sean impotentes, perjudican a la vida, a la seguridad de los instintos, son unos instrumentos inadaptados, lo que hace que «el hombre es, en proporción, el animal más fallido, el más enfermo, el que se ha alejado de manera más peligrosa de sus instintos. [...] La consciencia, el 'espíritu', nos parecen un síntoma de imperfección relativa del organismo, como un ensayo, una tentativa, una equivocación [Fehlgreifen]» ${ }^{44}$. Lo que se proclama aquí es la superioridad de la voluntad como instinto por encima de todas las formas de representación, las cuales son más bien un handicap que instrumentos seguros y auxilios para la vida. Pero también hay que resaltar que Nietzsche utiliza, para caracterizar la conexión de los instintos y de la voluntad con la acción y la virtud, el término bedingt, que indica la conexión ('genealógica', o 'fisiológica') de 'nuestra vida' con lo que la condiciona, con lo que necesita la vida, entre la vida y sus condiciones necesarias: nuestra vida tiene condiciones, nuestra vida condiciona ciertos actos y ciertas virtudes. Cuando esta conexión es rota, cuando el ser no es más que un ideal sin sus condiciones de vida o una voluntad que niega la vida, que la reniega en sus actos y representaciones, la vida es negada. Es esta negación de la vida la que Nietzsche llama moral, es aquello que define a la debilidad. Nietzsche ofrecerá más abajo algunos sinónimos metafóricos o figurativos de esta negación de la vida: «declive», «última debilitación de la vida», «chinería

${ }^{43}$ Crepúsculo de los ídolos, «Sentencias y flechas» $\$ 8$.

${ }^{44}$ El Anticristo $\$ 11$. 
königsberguense». La vida es aquello que se afirma, y lo que se afirma no puede ser más que la voluntad sin ideal, sin abstracción, sin racionalidad, sin universalidad, sin «idea del deber en general». Una voluntad por así decirlo que sea pura voluntad. Pero esta voluntad, como dirá Nietzsche en las últimas líneas de este escrito, no puede ser tal si no agota en ella misma y en ella sola su fuerza, su inspiración, su potencia. Nietzsche, en efecto, designa con 'virtud' la necesidad interna de la vida, la potencia espontánea, no representada, la fuerza originaria y propia de la fuerza. Esto es lo que él entiende por afirmación, en La genealogía de la moral, cuando habla de los fuertes y de la acción: «Toda moral noble procede de un decir-sí triunfante sobre sí mismo» ${ }^{45}$. Y es aquello que él designa aquí negativamente usando el término, muy vago, como hemos visto, de 'impersonalidad', de 'deber impersonal', que pretenden precisar las expresiones «Moloch de la abstracción» y «deber en general». Estas expresiones quieren definir lo que Nietzsche designa positivamente, pero de una manera demasiado concisa, hablando de «su deber» y proponiendo el lema, absurdo desde un punto de vista filosófico clásico y sobre todo desde el punto de vista kantiano: «Que cada uno se invente su virtud, su imperativo categórico». En sí es inepto, por contradictorio, intentar «inventar su imperativo categórico»: la universalidad y la invención son inconciliables, el imperativo no es categórico más que si sobrepasa el principio subjetivo constituido por la máxima, y la virtud no es una virtud más que si su validez es reconocida y supera las inclinaciones y las exigencias de la voluntad particular. Lo que Nietzsche intenta explicitar es lo que entiende por afirmación, que él llamará un poco más abajo «necesidad interior», «elección profundamente personal», e incluso «placer». Estas últimas expresiones significan que la voluntad fuerte y afirmativa es aquella que encuentra en ella misma su principio de mando y de comienzo. La virtud consiste en afirmar, comenzar, mandar $-\mathrm{y}$ en obedecer. Toda fuerza se debilita cuando somete su energía y su potencia, su «conservación y su crecimiento» a un «exterior», a «algo otro», a un «no-uno mismo» ${ }^{46}$. Decir sí, afirmar, la virtud, consiste en mandarse a sí mismo, en hallar en sí mismo su trascendencia, su principio de «crecimiento», su Selbstüberwindung, consiste en crear, crear su ley, no tener otra ley más que la necesidad interior, ser para sí mismo su propio legislador (es el sentido fuerte de la autonomía), su voluntad de poder. Cualquier otra moral es negación. Y aquí hallamos implícita la idea que el deber-ser, considerado por Platón como el summum del ser, como el ser en sentido pleno, hasta el punto que de la idea de Bien era el principio del deseo, y que no podríamos desear sino el Bien (principio socrático: «nadie es desgraciado por su propia voluntad»), es en efecto, según Nietzsche, una carencia de ser, un defecto de ser, una nada- es el

${ }^{45}$ La genealogía de la moral I, §10.

${ }^{46}$ Ibid. 
nihilismo. El origen de esta inversión del socratismo puede encontrarse en Schopenhauer, quien define el ser como voluntad y la voluntad como cosa en sí, pero como un principio de pulsión desordenada más que de atracción, de sufrimiento y de caos absurdo, más que de Bien y de fin suficiente, como un empuje sin meta y no como un télos, un tinos héneka que se basta a sí mismo $(\text { ikanon })^{47}$.

Volviendo a la idea de mando, a decir verdad Kant no contestaría las afirmaciones de Nietzsche, puesto que él inscribe su moral en el marco de un pensamiento del deber, del imperativo, es decir, de la necesidad. Para él, la obligación es un absoluto abstracto, mientras que para Nietzsche es necesidad interna, afirmación de sí. Si nos situamos desde la problemática de la autonomía, podríamos decir que en efecto, formalmente, las dos problemáticas comportan similitudes, pero con la diferencia considerable de que para Kant el absoluto (el deber, la ley) es la afirmación de sí como universal, mientras que para Nietzsche lo absoluto es la afirmación de sí como singularidad, necesaria por no ser universalizable. La autonomía kantiana es la libertad en tanto que es universalizable, mientras que para Nietzsche la libertad no puede ser más que la potencia propia de la voluntad y la universalidad designa una voluntad que sólo se quiere como no-yo, por alienación, por sumisión a una autoridad externa, el rebaño. Nietzsche ve en la universalidad una debilidad que busca algo que la garantice, que se quiere cómo y por lo otros, mientras que Kant ve en la universalidad de la máxima el remedio a los conflictos violentos entre las máximas subjetivas. ¿Pero podemos postular, como Nietzsche, que la guera es una noble competición, un Wettkampf donde las voluntades se refuerzan mutuamente en una rivalidad homérica? Y no habrá que preguntarse si el rebaño no ha aniquilado ya toda noción de autoridad (el nihilismo), incluso interior y personal, hasta el punto de que la universalidad constituye el único recurso contra el nihilismo tal cual Nietzsche lo entendía, la condición de la supervivencia, acaso si no de la paz, en un enfrentamiento donde la violencia dominante roe a las voluntades particulares exacerbadas en voluntades autónomas y fuertes, y donde el rebaño ha conseguido que el último hombre se haga pasar por individuo capaz de «inventar $s u$ virtud, $s u$ imperativo categórico» ${ }^{48}$. ¿El último hombre es una persona, una voluntad que se afirma?

Sea como fuere, ahora podemos entender mejor lo que Nietzsche entiende por afirmación. En un texto de Ecce homo en especial, es donde Nietzsche reafirma y re-explicita lo mejor posible sus tesis centrales sobre la afirmación, sobre la oposición entre el 'ideal', es decir la moral, y la realidad, entre la negación (nihilismo, decadencia) y la afirmación, entre el deber-ser como noser y el ser. Este texto resume y esquematiza, una vez más, la antítesis de la

${ }^{47}$ Cf. Platón, Lisis y República.

${ }^{48}$ Cf. P. Valadier, Nietzsche. Cruauté et noblesse du droit, Michalon, Paris, 1998. 
que Nietzsche ha hecho el tema central y el principio de su obra, y que ha designado numerosas veces con el simbolismo dionisíaco opuesto al simbolismo cristiano: «Yo vivo sin interrupción la auténtica antítesis: -el instinto que degenera, que se vuelve contra la vida con un rencor subterráneo (el cristianismo, la filosofía de Schopenhauer, y en cierto sentido ya la filosofía de Platón, todo el idealismo es una forma típica de ello) y una fórmula de la afirmación suprema, nacida de la abundancia, de la sobreabundancia, un decir-sí sin reservas incluso para con el sufrimiento, con el error, con todo lo extraño y dudoso de la existencia... Este sí último, el más alegre, el más exuberante y petulante hacia la vida, no es sólo la intuición suprema, sino también la más profunda, la más rigurosamente confirmada y mantenida por la verdad y la ciencia. Nada de lo que ha nacido debe ser descontado, nada está de más los aspectos de la existencia rechazados por los cristianos y otros nihilistas son incluso de un orden infinitamente más elevado en la jerarquía de los valores, respecto a lo que el instinto de décadence puede aprobar, llamar bueno [...]. El conocimiento, la afirmación de la realidad es para el fuerte una necesidad del mismo orden que para el débil la cobardía y la huida ante la realidad, -el 'ideal'- bajo la inspiración de la debilidad.... ${ }^{49}$

traducción de Marco Parmeggiani

${ }^{49}$ Ecce homo, «El nacimiento de la tragedia» $\$ 2$. 